\title{
ASO Author Reflections: The Changing Role of Gene Expression Profiling in ER+/HER2- Breast Cancer
}

\author{
Julia E. C. van Steenhoven, $\mathrm{MD}^{1,2}$, and T. van Dalen, $\mathrm{MD}, \mathrm{PhD}^{1}$ \\ ${ }^{1}$ Department of Surgery, Diakonessenhuis Utrecht, Utrecht, The Netherlands; ${ }^{2}$ Department of Pathology, University \\ Medical Center Utrecht, Utrecht University, Utrecht, The Netherlands
}

\section{PAST}

International guidelines increasingly question the benefit of adjuvant chemotherapy in selections of estrogen receptor-positive $(\mathrm{ER}+) /$ human epidermal growth factor receptor 2-negative (HER2-) breast cancer patients. ${ }^{1}$ At the same time, and in the same selection of patients, gene expression profiles (GEPs), such as the 70-gene signature (70-GS), are used as a means to better guide chemotherapy decisions. Previous studies demonstrated that use of the 70-GS was associated with a significant reduction in chemotherapy administration in patients with $\mathrm{ER}+1$ HER2 - disease of low or intermediate malignancy grade without overt lymph node metastasis $(\leq \mathrm{Nmi}){ }^{2}$ In the present study, we assessed recent trends in the administration of adjuvant chemotherapy in patients eligible for GEPs and evaluated the role of the 70-GS on chemotherapy administration in lymph node-negative (NO) and lymph node-positive $(\mathrm{N}+)$ breast cancer patients.

\section{PRESENT}

At a nationwide level, the overall administration of adjuvant chemotherapy in patients eligible for GEP use decreased from 49 to $23 \%$, while $70-$ GS use increased from

\footnotetext{
ASO Author Reflections is a brief invited commentary on the article "The Changing Role of Gene-Expression Profiling in the Era of Deescalating Adjuvant Chemotherapy in Early-Stage Breast Cancer." Ann Surg Oncol. 2019;26:3495-501.
}

(C) The Author(s) 2019

First Received: 30 September 2019; Published Online: 24 October 2019

J. E. C. van Steenhoven, MD

e-mail: juliavansteenhoven@gmail.com
24 to $51 \% .^{4}$ The decline in chemotherapy administration occurred without a change in national breast cancer guidelines, ${ }^{3}$ but coincided with recent international guideline recommendations. ${ }^{1}$ In contrast to previous studies, ${ }^{2}$ the observed decline in chemotherapy use between 2013 and 2016 occurred in N0 patients irrespective of 70-GS use, and mainly in N0 patients in whom the 70-GS was not used. In contrast, in $\mathrm{N}+$ patients, use of the 70-GS was strongly associated with a decreased likelihood of receiving chemotherapy throughout the study period. ${ }^{4}$ In the present study, the effect of age on the decision to administer adjuvant chemotherapy was remarkable. In patients $<50$ years of age and 50-59 years of age, the 70-GS was strongly associated with a decreased probability of receiving chemotherapy, whereas in older patients (60-69 years), a reversed association was observed. ${ }^{4}$

\section{FUTURE}

The present study reflects a growing restraint of clinicians to administer chemotherapy in selections of $\mathrm{ER}+/$ HER2 patients. In clinical low-risk (N0) patients, this leads to less patients receiving chemotherapy irrespective of 70-GS deployment. This is in line with the results of the recently published MINDACT trial, showing no additional value of the 70-GS in clinical low-risk patients. ${ }^{5}$ Efforts should be made to better delineate the category of $\mathrm{ER}+1$ HER2 - patients who are to be considered as clinical 'low risk' patients and who will not be candidates for chemotherapy use or 70-GS deployment. On the other hand, in categories of patients who are still considered as 'clinical high risk', e.g. younger women and node-positive patients, 70-GS use has an important impact in terms of a 70-GS use-associated decrease in the proportion of patients treated with adjuvant chemotherapy. In these latter patient categories, gene expression profiling should be more 
strongly advocated in order to avoid overtreatment. Longterm follow-up of ongoing trials into gene expression profiling will be crucial to corroborate this de-escalating approach.

DISCLOSURES Julia E. C. van Steenhoven reports no conflicts of interest.

OPEN ACCESS This article is distributed under the terms of the Creative Commons Attribution 4.0 International License (http://crea tivecommons.org/licenses/by/4.0/), which permits unrestricted use, distribution, and reproduction in any medium, provided you give appropriate credit to the original author(s) and the source, provide a link to the Creative Commons license, and indicate if changes were made.

\section{REFERENCES}

1. Coates AS, Winter EP, Goldhirsch A, et al. Tailoring therapiesimproving the management of early breast cancer: St Gallen
International Expert Consensus on the Primary Therapy of Early Breast Cancer 2015. Ann Oncol. 2015;26(8):1533-46.

2. Kuijer A, van Bommel ACM, Drukker CA, et al. Using a gene expression signature when controversy exists regarding the indication for adjuvant systemic treatment reduces the proportion of patients receiving adjuvant chemotherapy: a nationwide study. Genet Med. 2016;18(7):769-75.

3. Kwaliteitsinstituut voor de gezondheidszorg CBO VvIK. Landelijke Richtlijn mammacarcinoom; 2012.

4. Steenhoven JEC, Kuijer A, Schreuder K, et al. The changing role of gene-expression profiling in the era of de-escalating adjuvant chemotherapy in early-stage breast cancer. Ann Surg Oncol. 2019;26:3495-501.

5. Cardoso F, van't Veer LJ, Bogaerts J, Slaets L, et al. 70 gene signature as an aid to treatment decisions in early-stage breast cancer. N Engl J Med. 2016;375:717-29.

Publisher's Note Springer Nature remains neutral with regard to jurisdictional claims in published maps and institutional affiliations. 